\title{
Associated Factories and Time to Occurrence of Tuberculosis Among Children on HIV/AIDS Care in Assosa and Pawe General Hospitals North West Ethiopia: A Retrospective Cohort Study 2020
}

Fassikaw kebede Bizuneh ( $\square$ fassikaw123@gmail.com )

Jimma University Institute of Health

Tadese Tollosa Daba

Wollega University Institution of health, Faculty of Public health

Belayneh Mengist Mitike

Debre Markos Univecity College of Medicine and health Sciences

Tamrat sheawno Fikretsion

Jimma University Institute of Health

Belete Negese Negese

Debre birhan university collage of health and medicine science

\section{Research}

Keywords: Predictors of TB, HIV infected children, HIV/AIDS Care, Ethiopia

Posted Date: December 3rd, 2020

DOI: https://doi.org/10.21203/rs.3.rs-118270/v1

License: (c) (1) This work is licensed under a Creative Commons Attribution 4.0 International License.

Read Full License 


\section{Abstract}

Background: Tuberculosis (TB) incidence in peadtrics and children living with human immune-deficiency virus (HIV) is an emerging global concern. Although, the incidence of TB among adult HIV patients is exhaustively studied in Ethiopia, but among children on HIV/AIDS care is overlooked. Knowledge of the time when TB develops during successive follow up could be helpful for time relevant intervention strategies.

Methods: health institution based retrospective cohort study conducted among 421 children on HIV/AIDS from 2009-2018. Time to develop TB was defined as time from enrollment for ART care until development of TB among children on ART. Proportional hazard assumption was checked for each variable and no variable was found with Schoenfeld test $<0.05$. Variables with $P$-value $<0.25$ at bivariate Cox regression analysis were entered into multivariable Cox model. Multivariable Cox regression model with $95 \% \mathrm{Cl}$ and AHR was used to identify significant predictor variables to develop TB at $P<0.05$.

Result: Totally 421 children were followed for a total of 662.5 Person Years of observation (PYO). The maximum and minimum follow up time on ART was 0.37 and 4.49 years, respectively. The median age of the children on ART at enrollment was 8 years $(\mathrm{IQR}=2-15)$. The Overall incidence density of tuberculosis in HIV infected children was 9.6/ 100 PYOs $95 \% \mathrm{Cl}(8.06-10.3)$. Tuberculosis occurrence among HIV infected children was significantly associated within TB history of contact $A H R=3.7,95 \% \mathrm{Cl}(2.89-7.2)$, not started on cotrimoxazole(CPT) AHR=2.4: $95 \% \mathrm{Cl}(1.84-4.74)$, incomplete vaccination $\mathrm{AHR}=2.4,95 \% \mathrm{Cl}(1.32-4.5)$, sever stunting $A H R=2.99: 95 \% \mathrm{Cl}(1.2-7.81)$, having hemoglobin $(\mathrm{Hgb}) \leq 10 \mathrm{mg} / \mathrm{dl} \mathrm{AHR}=4.02,95 \% \mathrm{Cl}$ $(2.01-8.1)$.

Conclusion: More than $80 \%$ of TB incidences occurred during two years of follow up after ART started. So intensified screening of CPT\& therapeutic feeding is highly recommended for all children.

\section{Introduction}

The Intricate linkage of tuberculosis(TB) with HIV infection for the past three decades become major threat and hindrance for international public health effort to achieve Millennium development goal [1]. Globally, tremendous progress has been made over the past decades in diagnosing and treating of TB and achieved $2 \%$ per year new TB incidence reductions [2]. However, in 20176.4 million new incidence cases of TB were reported [3], among this $9 \%$ ( 0.3 million) were new incidence of TB-HIV co-infections and $50 \%$ of new infection including inborn seropositive children were located in resource limited settings [4]. It is mainly due to difficulty in timely addressing prophylaxis and ART treatment gaps [5]. On the other hand, absence of sophisticated early HIV diagnosis technologies for inborn HIV infected children [6] increase early mortality by lethal opportunistic infections, the commonest one is tuberculosis [7, 8]. It is one of the leading lethal opportunistic infection with 30-40\% lifetime incidence risk for seropositive children $[9,10]$. Global systemic review and meta-analysis on incidence of tuberculosis on people living with HIV/AIDS(PLWHV) in 2013 indicated, the incidence burden has variation in continental perspective 
[11], which is $31.25 \%$ in African countries, $25.06 \%$ in Latin America countries, $17.21 \%$ in Asian countries, $20.11 \%$ in European countries, and $14.84 \%$ in the USA [12]. Several studies in African countries have shown that the incidence of TB among HIV positive children ranges from 1-9.9 per 100 person years [911,13 ] with different times of immunological and pathophysiological response for tuberculosis incidence $[14,15]$. For instance tuberculosis occurrence in, Uganda \& Zimbabwe 1.9/100 P-Y [11], Tanzania 5.2/100 P-Y [10]. According to global TB report of 2018, Ethiopia found top 17 twine TB \& HIV epidemic countries with 8.6-17/1000 new TB incident including seropositive children [3],With each year, 3900 HIV infected children develop morbidity by opportunistic infection especially by TB [15].Childhood TB incidence during successive follow up varied in different regions and health institutions in Ethiopia [16]. For example, in Adama 6.03/100 P-Y [17], Debre Markos 2.63/100P-Y [18], Gondar 4.9/ 100 PY [19], Northern Ethiopia 4.2 / 100 P-Y [20] and southern Ethiopia2.6 /100 P-Y [21]. On the other hand, factors associated with TB incidence were identified [17-19, 22]. Notably ,functional status [20] WHO stage\& anemia [20, 23], residence[20], nutrition status [17] adherence status [18]. Currently, tuberculosis incidence among seropositive children is an emerging and global concern, in fact due to its one of leading lethal opportunistic infections [24]. Although, studies have been conducted on TB incidence among children on HIV/AIDS care in Ethiopia [4], however the time of TB occurrence among on HIV/AIDS care children is incompletely described and overlooked $[20,25]$. In addition, information on the time when TB develops is scarce $[11,19]$. The main aim of this research is to assess Associated Factories and Time to occurrence of Tuberculosis among seropositive children in Assosa and Pawe General Hospitals North West Ethiopia.

\section{Methods}

\section{Study area, design and population}

We conducted health institutions based retrospective cohort study among 421 children on HIV/AIDS care from January 1/2009 to December 31 /2018 at Assosa \& Pawe general hospitals in Benishangule Gumuz regions. Both hospitals are located in this regional state in North West Ethiopia. This region is one of the nine regions in Ethiopia. Assosa is the capital city of this region and it is located at a distance of $659 \mathrm{~km}$ in west of Addis Ababa and Pawe hospital is also located a distance from $565 \mathrm{~km}$ from Addis Ababa in North West direction. This region has currently 2 general and 3 primary hospitals with one regional laboratory. This two selected Hospitals are routinely diagnose and treat tuberculosis based on the clinical findings, chest x-ray, AFB and XpertTB for suspected TB patients [26]. In both general hospitals there has been given ART care service 2007 pediatric HIV/AIDS guideline [27]. Following the time of enrollment to ART care continuum, all children have started ARV at both hospitals. Among these, 238 and 191 children were on follow up and care at Assosa general hospitals and Pawe general hospitals, respectively. From the registration log book, eight children with incomplete outcome data were excluded from the study.

\section{Sample size determination and sampling procedure}

Sample size for this study was calculated by using EPI INFO software using the following parameters. A) (a) of $5 \%$, power $80 \%, \mathrm{Z}=$ within $95 \% \mathrm{Cl}=1.96$ and $\mathrm{AHR}=2.39[20](\mathrm{P} 1)=6.6 \%$ and $(\mathrm{P} 2)=15.8 \%$ obtained 
408 by adding $5 \%$ incomplete data final sample size will be 421 .Computer generated random number used for final study subject of study subject from two hospitals.

Totally there existed 1230 children started HIV/AIDS care and registered for SMART data care since January 1st /2009-31st December 2018. Since in Assosa general hospitals 723 and Pawe general hospitals 507 children started HIV/AIDS care and proportionally sample allocation is used based on their source population for 421 final sample sizes.

\section{Assosa Hospital $\quad$ N $1230 \quad$ Pawe Hospitals N 1230}

First by using Unique ART number of each individual card retrieved from SMART data set of pediatrics ward. Then by using computer generated random number 247 study participants from Assosa hospitals and 174 study participants from pawe general hospitals were recruited.

\section{Study variables}

In this study, the outcome variable was Time to develop TB; Incident TB cases were only those who developed new TB (EPTB \& PTB) during the follow up period. The outcome variables ascertained if TB occurred only after started ART during ART follow up times.

Independent variables included: Age of children, sex, residence, family size, WHO clinical stage TB contact history, CD4 counts, Hgb, functional status, Isoniazid preventive therapy, Cotrimoxazoles preventive therapy, vaccination status, weight for age (under nutrition), weight -for -height (wasting) and height -for-age (stunting).

\section{Operational definitions}

Case ascertainment: The outcome variables (TB) was diagnosed based on bacteriological, molecular, histopathology and clinical methods by using ( microscope, sputum culture, chest $\mathrm{x}$-ray, and Xpert or combinations) during patient presentation for TB symptoms [28].

Event: New occurrence of tuberculosis during HIV/AIDS care follows up times with study in periods.

Censored: HIV positive children who did not developed TB during HIV/AIDS follow up.

TB history of contact: Children during ART follow up before TB incidence developed, having history of survives or contact at any time with who has active PTB patient.

Opportunistic infection: for HIV infected children during the following if any one of diseased developed registered on $A R T$ follow up form by their code $(B P=$ Bacterial pneumonia,$U L=$ oral ulcer, $Z=$ Herpes zoster, $\mathrm{PCP}=$ pneumocystis carnie pneumonia, $\mathrm{DC} / \mathrm{DA}$ - chronic / acute diarrhea, $\mathrm{CT}$ = central nervous toxoplasmosis CM streptococcal meningitis [29]. 
CD4 :was classified as below the threshold according to the following age-specific thresholds: less than $15 \%$ for children aged $12-35$ months, less than $10 \%$ for children aged 36-59 months or less than 100 cells/mm3 for children aged 5-15 years [20].

Stunting, underweight and wasting: The child being 2 standard deviations (SDs) below the normal for height for age, weight for age, or weight for height, according to the WHO 2006 curve. For children under or equal age 2, wasting was measured by weight for length Z-score; for children above age 2, wasting was defined by Z-score. Z-score $\geq-2$ was defined as non-wasting; $-3 \leq Z$-score $\leq-2$ was defined as moderate wasting; Z-score $\leq-3$ was defined as severe wasting. Stunting was measured by height/length for age Z-score. Z-score $\geq-2$ was defined as non- stunting; $-3 \leq Z$-score $\leq-2$ was defined as moderate stunting; Z-score $\leq-3$ was defined as severe stunting $[10,17,22]$.

\section{Data collection tools, procedures, and quality control}

Four bachelor nurses and two supervisors were selected for data collection processes and all had took ART training. For quality of data collection process, one-day traing was given in two hospitals with two supervisors for data collectors. The principal investigator and two supervisor followed data. Data were collected using the data abstraction tool and medical history sheet prepared from Ethiopian Federal ministry of health HIV/AIDS follow up forms [15].

\section{Data processing and analysis}

Data entered into the computer using EPI-DATA version 3.1 \& exported to STATA 14.1 for cleaning and analysis. Descriptive analysis, such as tables, graphs, Kaplan Meier survival curve and log rank test was done. Hazard ratio with $95 \% \mathrm{Cl} \& \mathrm{P} \leq 0.05$ was used to measure association with independent variable. The overall survival graph and hazard failure estimated curve was used to show survival and hazed probability of risk group. Cox-regression model was fitted to identify predictors for incidence of pulmonary tuberculosis. All predictors that was associated with the outcome variables in the bivariable analysis at a hazard ratio of P-value 0.25 or lower was included in multi variable Cox-regression model. Variables with adjusted hazard ratio in multivariable Cox-regression with their corresponding $95 \%$ confidence interval with P-value $<0.05$ was considered as significant predictors .Cox-proportional hazard assumption was checked by (log-log plot) \& expected versus observed Kaplan Meier graph test for each variable with schoenfield residuals test for each variable. No variables less than $<0.05$.After multivariable cox regression was built by transforming from bivariable $\mathrm{P}<0.25$, for finally model selection was selected by AIC \& BIC criteria [30].Finally, model adequacy was checked by Nelson Alana and Cox Snell residual combination was used for checked model adequacy \& it became on straight line with Zero origin in $\mathrm{X}$ and Y axis.

\section{Result}

\section{Demographic characteristics of study participants}


From 429-study participant, 421 were included for final analysis and 8 cards were discarded due to incompleteness. The median age of children during this time was 9 years with (IQR $=2-15)$. More than one-third $39.5 \%$ of children were found at $6-10$ years age classification group. Slightly more than half $51.54 \%$ of children were female in sex, of them $52 \%$ were live in rural residence. Among the total study participant children $54.87 \%$ of them lived with $3-4$ family groups among $56.06 \%$ seropositive children lived with their family.

\section{Baseline clinical characteristic}

Nearly two- third (62.5\%) of study participants were addressed isoniazid. Regardless of HAART initiation after starting HIV/AIDS care in both hospital 126(29.5\%) children develops opportunistic infection. The most common opportunistic infection was identified, bacterial Pneumonia 53(35.9\%) \& Pneumocystis carnie pneumonia (PCP) $27(21.6 \%)$ respectively. More than two third of children (63.9\%) found WHO clinical stage $3 \& 4$. Among total study participant $147(34.92 \%)$ has hemoglobin $\leq 10 \mathrm{mg} / \mathrm{dl}$. From the total, two-third of children 276 (66.27\%) were completed their vaccinating.

Similarly nearly one fourth of $113(26.84 \%)$ HIV infected children CD4 count was below threshold level .Eighty percent of the children (80.24\%)has good functional status progression. Among the total study participants, $56(13.4 \%)$ has poor ART adherence. During the follow up times from 421 total study participants $199(47.8 \%)$ has on children cohort of follow up, $20(4.75 \%)$ drop totally from the follow up [Table 1]. 
Table 1

Base line socio demographic, clinical and laboratory characteristics of children on ART care at Assosa and Pawe General Hospitals since January 2009 - December 2018 EC

\begin{tabular}{|c|c|c|}
\hline Variables & $\begin{array}{l}\text { Frequency } \\
\mathrm{N}=421\end{array}$ & $\begin{array}{l}\text { Percent } \\
100 \%\end{array}$ \\
\hline Sex Male & 204 & 48.46 \\
\hline Female & 217 & 51.54 \\
\hline Age $<=5$ years & 87 & 20.67 \\
\hline $6-10$ & 146 & 34.39 \\
\hline >=11 years & 188 & 43.94 \\
\hline Residence Urban & 205 & 48.69 \\
\hline Rural & 216 & 51.31 \\
\hline Hemoglobin >10 mg/dl & 263 & 62.92 \\
\hline$<=10 \mathrm{mg} / \mathrm{dl}$ & 158 & 37.92 \\
\hline WHO stage $1 \& 2$ & 269 & 63.9 \\
\hline Stage $3 \% 4$ & 152 & 36.10 \\
\hline CD4 count Below threshold & 113 & 26.84 \\
\hline Above threshold & 308 & 73.16 \\
\hline Functional Appropriate & 338 & 80.24 \\
\hline Delay & 50 & 11.89 \\
\hline Regression & 31 & 7.84 \\
\hline Adherence Good & 224 & 57.96 \\
\hline Fair & 121 & 28.73 \\
\hline poor & 56 & 13.44 \\
\hline Isoniazid yes & 258 & 61.52 \\
\hline No & 163 & 38.48 \\
\hline Cotrimoxazoles yes & 321 & 76.26 \\
\hline No & 100 & 23.94 \\
\hline opportunistic infections yes & 126 & 29.93 \\
\hline No & 295 & 70.07 \\
\hline
\end{tabular}




\begin{tabular}{|lll|}
\hline Variables & Frequency & Percent \\
& $\mathbf{N}=\mathbf{4 2 1}$ & $\mathbf{1 0 0 \%}$ \\
\hline Vaccination Completed & 276 & 66.27 \\
\hline Defaulted & 76 & 18.2 \\
\hline Not registered & 69 & 16.05 \\
\hline TB contact history Yes & 135 & 32.8 \\
\hline No & 286 & 68.17 \\
\hline Family size <=2 & 133 & 31.83 \\
\hline 3-4 & 219 & 52.21 \\
\hline 5-6 & 50 & 11.88 \\
\hline$>=7$ & 19 & 4.09 \\
\hline Children status being on follow up & 199 & 47.7 \\
\hline Lost from follow up & 43 & 10.23 \\
\hline Transfer in to adult & 91 & 21.62 \\
\hline Transfer out & 56 & 13.30 \\
\hline Died & 12 & 2.85 \\
\hline Drop & 20 & 4.75 \\
\hline ART regiment Changed & 85 & 20.24 \\
\hline Not changed & 336 & 79.2 \\
\hline
\end{tabular}

\section{Baseline Nutritional status of HIV infected children}

From the total 421 study participant, 33 (7.84\%) children developed sever stunting (HFA<-3 Z score), also $72(17.10 \%)$ study participant developed moderate wasting (HFA) between - 3- -2 Z score finally 313 (74.35\%) HIV infected children remain above >-2 Z score.

\section{Tuberculosis incidences rate}

At the end of the follow up periods, 667.7 Person Years (PYOs) of observation was obtained. During this time 64 new TB incidences occurred, of this 30 were pulmonary tuberculosis and the remaining 34 were extra pulmonary tuberculosis. The cumulative incidence rate 64 TB case found (15.64\%) occurred. Totally, 64-event alone took 88.2 PYOs of observation taking during follow up. The overall incidence density of tuberculosis was found 9.6 person/100 years $95 \% \mathrm{Cl}(8.06-10.3)$. 


\section{Survival status of HIV infected children}

Three hundred fifty-seven (84.79\%) observation was censored at the end of the follow up times. During this time 556.8 Person-years of risk, time was observed with minimum and maximum of 0.39 and 4.5 years of observation obtained respectively [Table 2].

Table 2

summary of TB free survival rate of HIV infected children at Assosa and Pawe General Hospitals since 2009-2018

\begin{tabular}{|llllll|}
\hline Time in years/month & Survival rate & $95 \% \mathrm{Cl}$ & New events & $\begin{array}{l}\text { Cumulative } \\
\text { frequency }\end{array}$ & $\begin{array}{l}\text { Frequency } \\
\%\end{array}$ \\
\hline 1 years & & & & 20 & $31.3 \%$ \\
\hline 2 years & $96.04 \%$ & $93.62-97.56$ & 20 & 53 & $82.3 \%$ \\
\hline 3 years & $82.62 \%$ & $77.80-86.49$ & 33 & 63 & $98.1 \%$ \\
\hline 4 years & $77.65 \%$ & $71.57-82.59$ & 10 & 64 & $100 \%$ \\
\hline$\geq 5$ years & $68.92 \%$ & $53.32-80.22$ & 1 & 64 & $100 \%$ \\
\hline
\end{tabular}

\section{Predictors for Tuberculosis}

During bivariables analysis totally 16 variables were selected in the first steps of model building and 10 variable selected, as the best model by comparing their model Asian information criteria (AIC) and Bayesians information criteria (BIC), which include (age, isoniazid preventive therapy, Cotrimoxazole preventive therapy, TB history of contact, vaccination status, height for age, who clinical stage, CD4 count, Hemoglobin, adherence) involved in multivariable analysis. Five of among predictors, TB history of contact, not started on cotrimoxazole. Incomplete vaccination, sever stunting, having Hemoglobin $\leq$ $10 \mathrm{mg} / \mathrm{dl}$ were found have statically significant with outcome variables [Figure2 ].Based on this, the risks of developing TB among HIV infected children for not started cortimoxazole is 2.4 times increase as compared with taking cotrimoxazole $(\mathrm{AHR}=2.4: 95 \% \mathrm{Cl}, 1.84-4.74)$ [Table 3]. 
Table 3

Bivariable and multi variable cox-proportional hazard analysis for predictors of TB among children treated on ART OPD at Assosa and Pawe General Hospitals 2009-2018

\section{Survival status of children}

Multivariable cox regression

\begin{tabular}{|c|c|c|c|c|c|}
\hline Variables & $\begin{array}{l}\text { TB } \\
\text { incidence }\end{array}$ & Censored & $\mathrm{CHR} 95 \% \mathrm{Cl}$ & $\begin{array}{l}P \text { - } \\
\text { value }\end{array}$ & $\mathrm{AHR}=95 \% \mathrm{Cl}$ \\
\hline Age of children $<=5$ years & 2 & 85 & 1 & & \\
\hline $6-10$ years & 12 & 134 & $\begin{array}{l}3.4(0.7 \\
15.52)\end{array}$ & 0.68 & $1.38(0.28$ 6.6) \\
\hline$>=11$ years & 50 & 138 & $\begin{array}{l}\text { 12.(12.7 } \\
49.6)\end{array}$ & 0.12 & 2.89 (0.62 12.) \\
\hline Isoniazid yes & 15 & 243 & 1 & & 1 \\
\hline No & 49 & 114 & $\begin{array}{l}6.58(3.6 \\
11.7)\end{array}$ & 0.80 & $0.91(0.411 .9)$ \\
\hline Cotrimoxazoles yes & 28 & 293 & 1 & & 1 \\
\hline No & 36 & 64 & $\begin{array}{l}4.7(2.87 \\
7.75)\end{array}$ & 0.003 & $2.5(1.44 .74)^{\star}$ \\
\hline TB history of contact Yes & 53 & 82 & $\begin{array}{l}12.21(6.6 \\
23.4)\end{array}$ & 0.002 & $3.7(2.897 .2)^{\star}$ \\
\hline No & 11 & 275 & 1 & & 1 \\
\hline $\begin{array}{l}\text { Vaccination status } \\
\text { Complete }\end{array}$ & 23 & 253 & 1 & & 1 \\
\hline Default & 33 & 43 & $\begin{array}{l}5.75(3.4, \\
9.72)\end{array}$ & 0.005 & $2.6(1.324 .5)^{\star}$ \\
\hline Not registered & 8 & 61 & $\begin{array}{l}1.24(0.5 \\
2.87)\end{array}$ & 0.25 & $1.68(0.664 .1)$ \\
\hline $\begin{array}{l}\text { CD4 count Above } \\
\text { threshold }\end{array}$ & 28 & 280 & 1 & & 1 \\
\hline Below threshold & 36 & 77 & $\begin{array}{l}1.58(0.91 \\
2.74)\end{array}$ & 0.403 & $\begin{array}{l}0.72(0.37 \\
1.42)\end{array}$ \\
\hline Adherence Good & 21 & 223 & & & 1 \\
\hline Fair & 15 & 104 & $\begin{array}{l}1.9(0 . .89 \\
4.07)\end{array}$ & 0.817 & $1.2(0.48,2.94)$ \\
\hline Poor & 28 & 30 & $\begin{array}{l}7.1(0.37 \\
26.32\end{array}$ & 0.746 & $1.19(0.522 .71)$ \\
\hline $\begin{array}{l}\text { Height for age (HFA) } \\
\text { Normal }\end{array}$ & 35 & 249 & 1 & & 1 \\
\hline
\end{tabular}




\begin{tabular}{|lcclll|}
\hline Survival status of children & \multicolumn{3}{c|}{} & \multicolumn{2}{c|}{$\begin{array}{c}\text { Multivariable cox } \\
\text { regression }\end{array}$} \\
\hline Moderate & 21 & 83 & $\begin{array}{l}1.64(0.95 \\
2.82)\end{array}$ & 0.06 & $1.32(0.622 .71$ \\
\hline Sever stunting & 8 & 25 & $\begin{array}{l}1.93(0.89 \\
4.1)\end{array}$ & 0.03 & $2.96(1.27 .88)^{\star}$ \\
\hline WHO stage 1\&2 & 14 & 255 & 1 & & 1 \\
\hline Stage 3\&4 & 50 & 102 & $9.1(4.916 .4)$ & 0.07 & $2.1(0.99$. \\
\hline Hemoglobin > 10 mg/dl & 12 & 251 & 1 & & 1 \\
\hline$<=10 \mathrm{mg} / \mathrm{dl}$ & 52 & 106 & $\begin{array}{l}9.62(5.13 \\
18.0)\end{array}$ & 0.001 & $4.02(2.18 .1)^{\star}$ \\
\hline
\end{tabular}

The risks of developing TB among HIV infected children having previous TB history of contact is 3.8 times increased as compared with no previous TB history of contact (AHR $=3.8: 95 \% \mathrm{Cl}, 2.89-7.2)$. The risks of developing TB among HIV infected children having incomplete vaccination was 2.4 times increase as compared with completed vaccination during their life time (AHR $=2.4$ : $95 \% \mathrm{Cl}, 1.32-4.5)$. The risks of developing TB among HIV infected children having Sever stunting 2.99 times increase as compared with HIV infected children having normal height for their age (AHR $=2.99: 95 \% \mathrm{Cl}, 1.2-7.81$ ). The risks of developing TB among HIV infected children having Hemoglobin $\leq 10 \mathrm{mg} / \mathrm{dl}$ times increase as Compared with hemoglobin $\geq 10 \mathrm{mg} / \mathrm{dl}$ (AHR $=4.02: 95 \% \mathrm{Cl}, 2.01-8.1)$. Model adequacy of this multivariable cox regression was checked by Nelson Alan and Cox Snell residual combination test. [Figur3].

\section{Discussion}

The finding of this study indicated that the overall incidence of tuberculosis was found 9.6/ 100 Person per years (PYOs) $95 \% \mathrm{Cl}(8.06-10.39)$. This is not comparable with study finding in southern Ethiopia 2.6/ 100 PYOs[21], Debre Markos 2.63 /100 PYOs [18], Gonder 4.9/ 100 PYOs [19], Adama 6.03 /100 PYOs [17]. In fact the study area has predominant distribution of tuberculosis [26]. The finding of this study revealed that not started Cotrimoxazoles prophylaxis was independently associated with occurrence of TB. This is agreed with northern Ethiopia [20] Adama hospitals[17].This might be due to Cotrimoxazoles preventive therapy significantly reduces HIV related morbidity and mortality from lethal opportunistic infections [3]. On the same way, seropositive children having TB history of contact is associated with TB incidence. This is in line with south Africa[9].In fact lack of awareness about transmission of TB might easily acquire the infection from nearby active patients[33]. Also this study indicates; having incomplete vaccination was significantly associated with TB occurrence. This is similar with finding in Adama [17] and Gondar [19]. On the same way HIV infected children having sever stunting was independently 
associated with incidence of TB. This in line with the study finding Tanzania[10] and Uganda \& Zimbabwe [11]. The fact is human immune virus increases nutrient mal-absorption due to metabolic alterations that culminate in weight loss and stunting with time leads early exposed for opportunistic infections [29],this facilitate rapid viral replication consumed body energy and create arena for incidence of TB $[2,34]$.This study finding also showed that children having hemoglobin $\leq 10 \mathrm{mg} / \mathrm{dl}$ was independently associated with TB incidence as compared with hemoglobin level $>10 \mathrm{mg} / \mathrm{dl}$ having children. This is in line with the study finding in Adama hospitals [17],university of Gonder [19], Dar es Salaam, Tanzania[10], England and wales[23]. In fact hemoglobin levels had high predictive value for incident TB and death's , and incidence TB is directly associated with severe anemia [35]. Regardless of starting HAART moderate or severe anemia can be independent predictor for TB $[35,36]$.

\section{Limitation of the study}

Retrospective nature of this study is one of the limitations of this study .due to this some of clinical important predictor variable which has independently associated with incidence of TB occurrence in other studies like educational status of children, economic status of family were not included in these study.

\section{Conclusion}

Incidence of TB was an important medical problem for children living with HIV ART treated in both Hospitals. This study finding concluded that baseline not ever taking cotrimoxazoles, ,having moderate stunting ,hemoglobin level lower than standard, incomplete vaccination ,having previous history of contact with TB has significantly and independently associated TB incidence. So intensified screening of cotrimoxazoles and malnutrition was highly recommended for intervention.

\section{Abbreviations}

AFB : Acide Fast Baccilli, AIDS: Acquired Immunodeficiency Syndrome; AHR: adjusted hazard ratio; ART: highly active antiretroviral therapy; CD4: Cluster of Differentiation 4; Cl: confidence interval; EPTB ,extra pulmonary tuberculosis CPT: cotrimoxazoles prophylactic therapy,IPT isoniazid prophylaxis therapy, PTB pulmonary tuberculosis, PLWH: people living with HIV/AIDS, Ols: opportunistic infections; WFA= weight for age, HFA =height for age, WFH= weight for height WFH: Weight for Height, WFA: Weight for Age, HFA: Height for Age, PYOs: Person Years of Observations.

\section{Declarations}

\section{Ethics statement}

Ethical clearance was obtained from the ethical review committee of Debre Markos University, College of Health Sciences (Ref. No: HSC/984/16/12). A formal letter were submitted on both Assosa and Pawe general hospitals for permission to be done entitled research articles, Time to develop pulmonary 
tuberculosis, predictors among HIV infected children receiving antiretroviral therapy, within two general hospitals, and permission was assured. All information collected from patient cards was kept strictly confidential and the names of patients were not included in the checklist. Confidentiality consent was not needed as it was a retrospective study was conducted on secondary data.

\section{Funding}

Not applicable

\section{Acknowledgment}

I would like to thank Pawe and Assosa general hospitals, administrative staffs, and data collectors assisting during data collection.

\section{Data availability}

The datasets analyzed during the current study are available from the corresponding author upon reasonable request.

\section{Consent for publication}

No consent for publication

\section{Competing interests}

The authors declare that they have no competing interests.

\section{References}

1. Getahun H, Gunneberg C, Granich R, Nunn P: HIV infection-associated tuberculosis: the epidemiology and the response. Clinical infectious diseases : an official publication of the Infectious Diseases Society of America 2010, 50 Suppl 3:S201-207.

2. WorldHealthOrganizations.: Antiretroviral therapy for HIV infection in infants and children: towards universal access. revisedmanau/ 2010 WHO Library Cataloguing-in-Publication Data(ISBN 978924 $1599801)$.

3. WHO: Global TB report, WHO genava 2018. 2018, 227.

4. Ausman Ahmed DM, Atsede M Shiferaw, Fanuel Belayneh,, Yenit MK: Incidence and determinants of tuberculosis infection among adult patients with HIV attending HIV care in north-east Ethiopia: a retrospective cohort study. BMJ 2018 V.8:e(doi:10.1136/).

5. Minaleshewa Biruk BA, 3, Senafekesh Biruk aFZA: Treatment Outcomes of Tuberculosis and Associated Factors in an Ethiopian University Hospital. Hindawi 2016, Volume 2016, Article ID 8504629, 9;2.

6. UNAIDS: State of HIV epidemic repeort b: UNAIDS report 2018. 
7. Li N, Manji KP, Spiegelman D, Muya A, Mwiru RS: Incident tuberculosis and risk factors among HIVinfected children in Tanzania. AIDS (London, England) 01 May 2013, 27(8):1273-1281 27 PMC4742782):29.

8. Jahromi K, Sharifi-Mood B: Pulmonary Tuberculosis in Children. Int J Infect 2014, 1(DOI: 10.17795/iji-21116):e21116.

9. N. A. Martinson H. Moultri RvNGB, A. Coovadia§, M. Cottonฯ, A., Violari GEGEC, J. A. Mclntyre*, and T. Meyersł: HAART and Risk of tuberculosis in HIV-infected South African children: a multi-site retrospective cohort. International Journal of Tuberc and Lung Disuberc Lung Diseas 2009 13(7): 862-867(HHS Author Manuscripts PMC6374123).

10. Nan LI KPM, Donna SPIEGELMAN,: Incident tuberculosis and risk factors among HIV-infected children in Dar es Salaam, Tanzania. 2016.

11. Angela M. Crook A. Anna Turkova VM, Mutsa Bwakura-Dangarembizi Sabrina Bakeera-Kitaka, et.al. PN-N: Tuberculosis incidence is high in HIV-infected African children but is reduced by co-trimoxazole and time on antiretroviral therapy. BMC Medicine 2016, 14(DOI 10.1186/s12916-016-0593-7): 2 of 11.

12. Junling Gao PZ, Hua Fu: Prevalence of TB/HIV co-infection in countries except China: a systematic review and meta-analysis. PloS one 2013, 8.

13. Badri M, Wilson D, Wood R: Effect of highly active antiretroviral therapy on incidence of tuberculosis in South Africa: a cohort study. The Lancet 2002, 359(9323):2059-2064.

14. Varaineb MMLLPPFFV, Daniel B: Tuberculosis after HAART initiation in HIV-positive patients from five countries with a high tuberculosis burden. CONCISE COMMUNICATION2006, AIDS 2006, Vol 20 No 9(ISSN 0269-9370 Q 2006 Lippincott Williams \& Wilkins):5.

15. FMOH: National guidelines for comprehensive HIV prevention, care and treatment. Manua/2014 https://aidsfree.usaid.gov/sites/default/files/ethiopia_natl_gl_2014.pdf:145.

16. EHNRI: ETHIOPIAN National TB/HIV ONE YEAR Sentinel Surveillance (July 2011 - June 2012). Reports 2013,

17. MasinoTessuBeshir AHB, Kenean Getaneh Tlaye , Tefera Mulugeta Demelew: Incidence and predictors of tuberculosis among HIV-positive children at Adama Referral Hospital and Medical College, Oromia, Ethiopia: a retrospective follow-up study. Epidemiology and Health 2019, 41(https://doi.org/10.4178/epih.e2019028):8.

18. N. EAHET: Incidence of tuberculosis in children on antiretroviral therapy: a retrospective cohort study. BMC research notes 2018, 11:https://doi.org/10.1186/s13104-13018-13846.

19. GebeyawSA. AddisK AK: Incidence and Predictors of Tuberculosis among HIV PositiveChildren at University of Gondar Referral Hospital, Northwest Ethiopia: A Retrospective Follow-Up Study. Hindawi 2015, Volume 2015, Article ID 307810, 6

20. Yihun Mulugeta Alemu GA, Ejigu Gebeye.: High Incidence of Tuberculosis in the Preventive Therapy in Children Living with HIV in Northern Ethiopia: A Retrospective Follow-Up Study. PLoS ONE 11(4) 2016, PLoS ONE 11(4):e0152941( DOl:10.1371/journal.pone.0152941):10. 
21. Yirdaw KD, Jerene D, Gashu Z, Edginton ME, Kumar AM, Letamo Y, Feleke B, Teklu AM, Zewdu S, Weiss $B$ et al: Beneficial effect of isoniazid preventive therapy and antiretroviral therapy on the incidence of tuberculosis in people living with HIV in Ethiopia. PloS one 2014, 9(8):e104557.

22. MuW.ZhaoY.SunX.Ma YY, L.Liu, X.Zhao, D.Dou, Z.Fang H.Zhang,: Incidence and associated factors of pulmonary tuberculosis in HIV-infected children after highly active antiretroviral therapy (HAART) in China: a retrospective study. AIDS care 2014, 26

23. A. T. Brennan RB, * K. Schnippel,§ R. Berhanu,§ M. Maskew, † L.: Incident tuberculosis in HIV-positive children, adolescents andadults on antiretroviral therapy in South Africa. INT J TUBERC LUNG DIS 20(8):1040-1045 2016, INT J TUBERC LUNG DIS 20(8):1040-1045

24. Sudjaritruk T, Maleesatharn A, Prasitsuebsai W, Lumbiganon P, Kumarasamy N, Kurniati: Prevalence, characteristics, management, and outcome of pulmonary tuberculosis in HIV-infected children in the TREAT Asia pediatric HIV Observational Database (TApHOD). AIDS patient care and STDs 2013, 27(12):649-656.

25. Tavitiya Sudjaritruk Alan Maleesatharn Wasana Prasitsuebsai, Siew Moy Fong NOL: Prevalence, Characteristics, Management, and Outcome of Pulmonary Tuberculosis in HIV-Infected Children inthe TREAT Asia Pediatric HIV ObservationalDatabase (TApHOD). CLINICAL AND EPIDEMIOLOGIC RESEARCH 2013, Volume 27, Number 12, (DOI: 10.1089/apc.2013.0236).

26. Haimanot Disassa KTT, Adane Worku,: A Preliminary Study on Molecular Characterization of Mycobacterium tuberculosis in Benishangul Gumuz Region, Western Ethiopia. British Microbiology Research Journal 2015.

27. FMOH : Guidelines for Paediatric HIV/AIDS Care and Treatment in Ethiopia. Guidelines 2007, https://apps.who.int/medicinedocs/en/m/abstract/Js19145en/.

28. FMOH: Guidelines for clinical and programmatic management of TB, leprosy and TB/HIV in ethiopia. guideline 2012.

29. FMOH: NATIONAL GUIDELINES FOR COMPREHENSIVE HIV PREVENTION, CARE AND TREATMENT. GUIDELINE 2017.

30. M.ail KK, J.M. Samet,Tsiatis,Wong,David Kleinbaum and Mitch Klein: Statistics for Biology and Health for survival analysis self learning book 2012.

31. WHO: Global tuberculosis control Geneve REPORT 2015, 20th (ISBN 978924156505

32. world health Organization: GLOBAL TB REPORT OF 2013. 2013.

33. A.Magadi2 Pga: Socioeconomic Status and Vulnerability to HIV Infection in Uganda: Evidence from Multilevel Modelling of AIDS Indicator Survey Data. AIDS research and treatment 2018, 20(https://doi.org/10.1155/2018/7812146):20.

34. Jorge OAlarcoClaudete AA, Laura Freimanis-Hance, Margot Krauss, Mary F. Reyes, jo Cardoso: Opportunistic and Other Infections in HIV-Infected Children in Latin America Compared to a Similar Cohort in the United States. AIDS RESEARCH AND HUMAN RETROVIRUSES 2011, Volume 28, Number 3, 2012(DOI: 10.1089/aid.2011.0057). 
35. Amanda Mocrofta OK, Simon E. Bartonc, Manfred Dietrichd, Rui Proencae: Anaemia is an independent predictive marker forclinical prognosis in HIV-infected patients fromacross Europe. Anaemia and clinical prognosis Mocro 1999, , Vol 13 No 8(AIDS. 1999 May 28;13(8):943-50.).

36. Andrew D Kerkhoff1, 3*, Robin Wood3,4, Frank G Cobelens2,5, Ankur Gupta-Wright4, The predictive value of current haemoglobin levels for incident tuberculosis and/or mortality during long-term antiretroviral therapy in South Africa: a cohort study. BMC Medicine (2015) 13:70 2015, DOI $10.1186 / \mathrm{s} 12916-015-0320-9$.

\section{Figures}

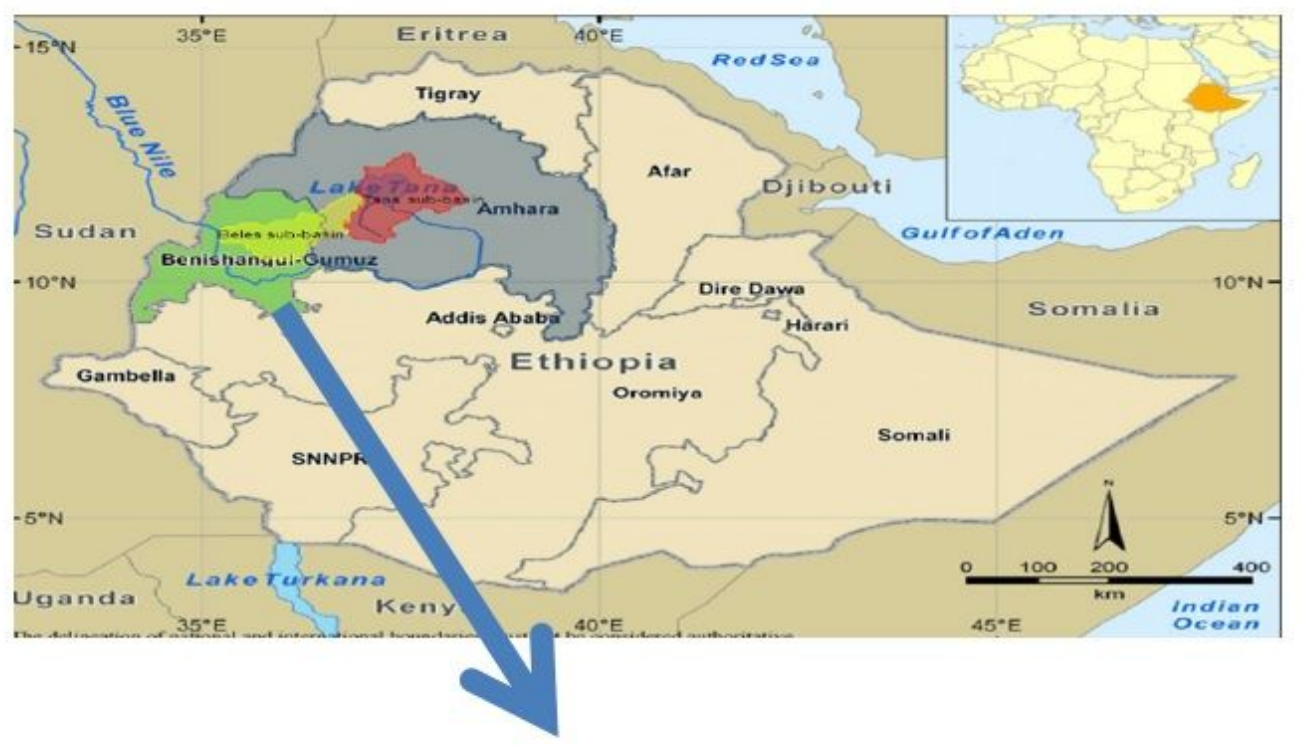

MAP OF BENISHSANGULE GUMUZE REGIONAL STATES

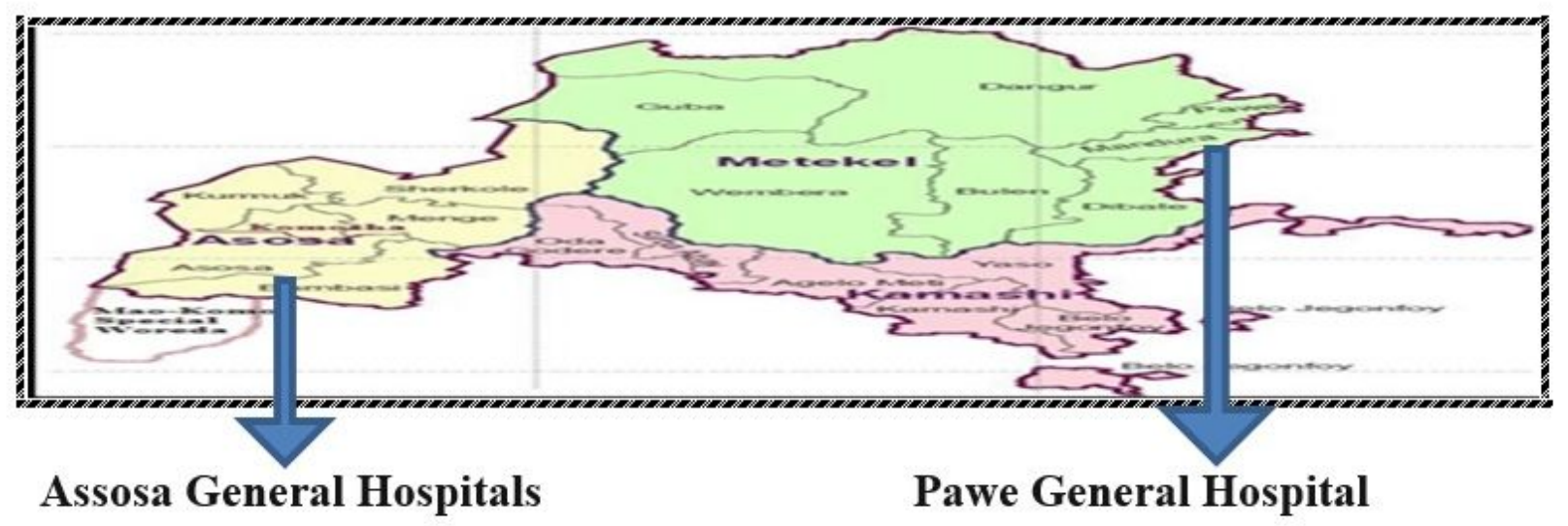

Figure 1 
Adapted from https://www.Map of Benishangule Gumuz Regional state. Note: The designations employed and the presentation of the material on this map do not imply the expression of any opinion whatsoever on the part of Research Square concerning the legal status of any country, territory, city or area or of its authorities, or concerning the delimitation of its frontiers or boundaries. This map has been provided by the authors.

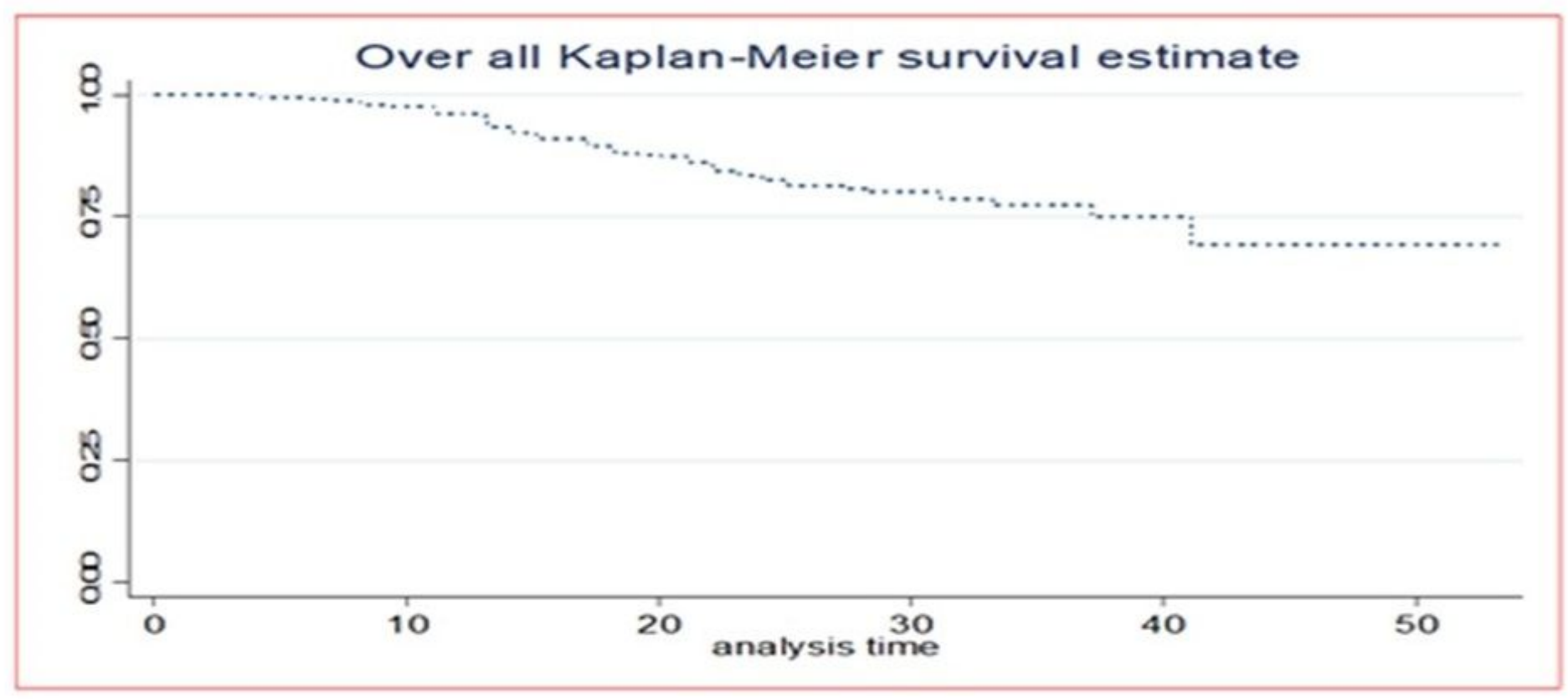

\section{Figure 2}

The overall Kaplan-Meier TB free survival probability of HIV infected children in two general hospitals since 2009-2018. 


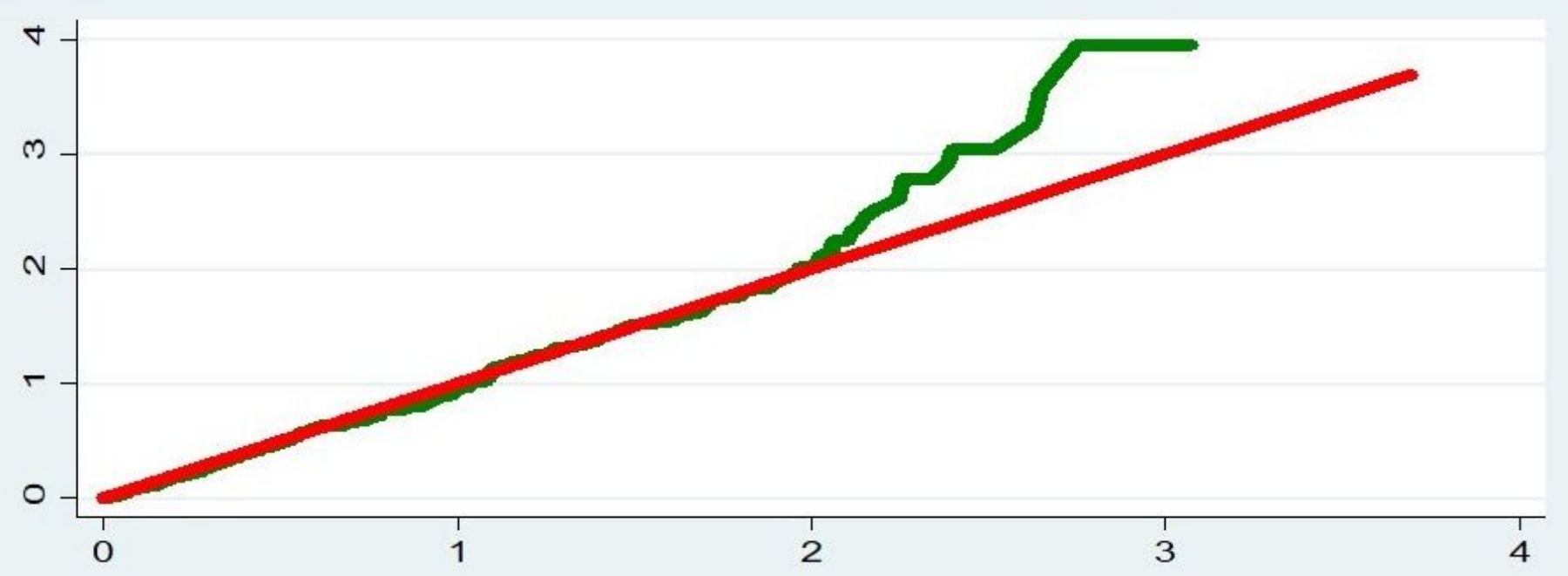

Nelson Alane and Cox-Snell reidual test for model adequcy

\section{Figure 3}

Final model adequacy checking by Nelson-Alone and Cox-Snell residual test after comparing multivariable-Cox regression models by $\mathrm{AIC}$ and $\mathrm{BIC}$ for titles of factors associated and time to occurrence of TB among HIV infected since 2009-2018 